\title{
Prevalence of cerebral venous thrombosis with the use of oral contraceptive pills during the Holy month of Ramadan
}

\author{
Mohammed AlSheef, MD, Mastourah Alotaibi, PharmD, Abdul Rehman Z. Zaidi, MD, Areej Alshamrani, PharmD, \\ Aroub Alhamidi, PharmD, Syed Ziauddin A. Zaidi, MD, Noor Alanazi, PharmD, Sarah Alhathlool, PharmD, \\ Ohoud Alarfaj, PharmD, Mohammed AlHazzaa, MSD, Ghaydaa Kullab, MD, Amany Alboghdadly, PharmD, \\ Amani Abu-Shaheen, MPH.
}

\begin{abstract}

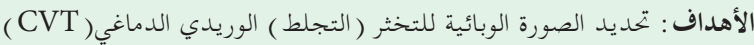

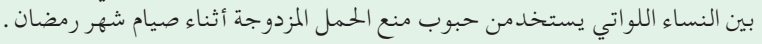

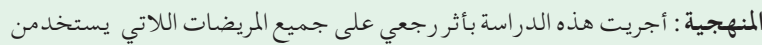

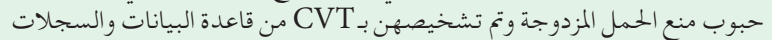

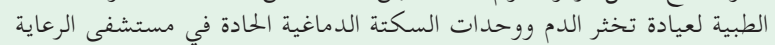

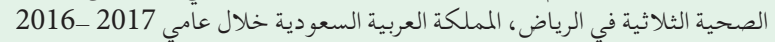

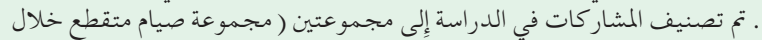

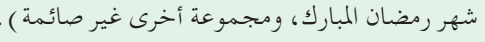

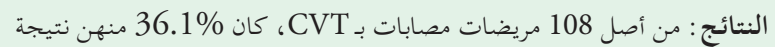

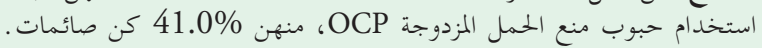

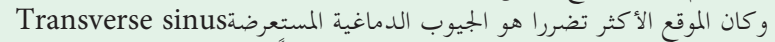
thrombosis

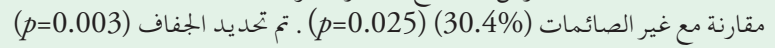

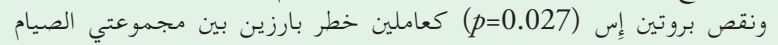

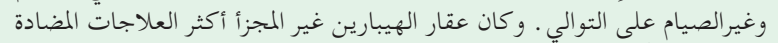

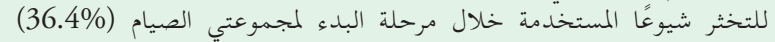

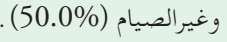

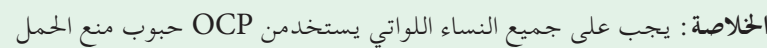

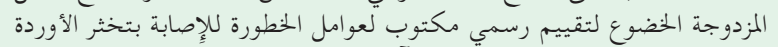

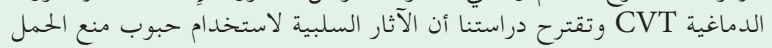

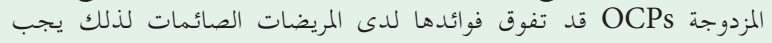

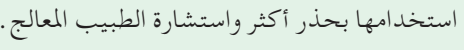

Objectives: To identify the epidemiologic profile of cerebral vein thrombosis (CVT) among fasting women using oral contraceptive pills (OCPs) during the holy month of Ramadan.

Methods: This retrospective study was conducted on all patients diagnosed with CVT and using OCPs from records at a tertiary care hospital in Riyadh, Saudi Arabia during 2016-2017. The study participants were categorized into 2 groups (an intermittently fasting group during the holy month of Ramadan and a nonfasting group).
Results: Out of 108 female patients with CVT, $36.1 \%$ were secondary to OCP, of whom $41 \%$ participants were fasting. The most affected site was the transverse sinus. Holocephalic headache was more common amongst fasting group $(68.8 \%)$ compared to non-fasting group $(30.4 \%)(p=0.025)$. Dehydration $(p=0.003)$ amongst the fasting group and protein $S$ deficiency $(p=0.027)$ in the non-fasting group were identified as the 2 prominent risk factors. Unfractionated heparin was the most common anticoagulant therapies used during the initiation phase for non-fasting (36.4\%) and fasting groups (50\%).

Conclusion: All women who are using OCP should undergo formal written risk assessments for factors of CVT. Our study suggests that the negative effects of OCPs use might outweigh its benefits; thus, it should be prescribed with caution, more so in fasting patients.

Keywords: thrombosis, fasting, contraceptives, oral, venous thrombosis, venous thromboembolism, Ramadan

Saudi Med J 2020; Vol. 41 (10): 1063-1069 doi: 10.15537/smj.2020.10.25397

From the Department of Medicine (AlSheef, Zaidi A, Kullab), from Department of Adult Hematology/BMT (Zaidi S), from the Department of Clinical Pharmacy (Alarfaj), from the National Neuroscience Institute (AlHazzaa), from the Research Center (Abu-Shaheen), King Fahad Medical City; and from the College of Pharmacy (Alotaibi, Alshamrani, Alhamidi, Alanazi, Alhathlool, Alboghdadly), Princess Nourah Bint Abdulrahman University, Riyadh, Kingdom of Saudi Arabia.

Received 29th June 2020. Accepted 8th September 2020.

Address correspondence and reprint request to: Dr. Mohammed AlSheef, Department of Medicine, King Fahad Medical City, Riyadh, Kingdom of Saudi Arabia. E-mail: malsheef@kfmc.med.sa ORCID ID: https://orcid.org/0000-0003-1651-1158 
$\mathrm{C}$ erebral venous thrombosis (CVT) is a rare condition that can lead to significant morbidity and mortality. Annually, there are 3 to 5 cases of CVT per million, which represents approximately $0.5-1 \%$ of all stroke cases. ${ }^{1}$ Cerebral venous thrombosis can present with headaches, seizures, focal neurological signs, and a decreased level of consciousness. Clinical judgment of CVT relies on clinical presentations that confirm diagnostic criteria, such as computed tomography (CT) and magnetic resonance angiography (MRA). ${ }^{2}$ However, due to diversity and a lack of unified clinical presentation of CVT, the diagnosis is either under-reported or misdiagnosed. ${ }^{3,4}$ One of the predisposing factors of CVT is using oral contraceptive pills (OCPs). ${ }^{5}$ In the early 1960s, the first OCP was introduced. Shortly after, health care professionals reported thrombosis cases of women using OCP, which led to increased research in this area. ${ }^{6}$ According to several observational studies, females who consumed OCP had an increased risk of CVT by 5-22 folds. 4,5

Currently, there are inadequate studies on the epidemiology of CVT from the Middle Eastern countries, including Saudi Arabia. An understanding of specific CVT risk factors in particular patient groups is needed to maximize prevention. Moreover, religion, tradition, socioeconomic, and educational factors differ in OCP use among countries. Intermittent fasting can be categorized into religious and non-religious fasting. All types of non-religious intermittent fasting include restriction of caloric intake, however, in each non-caloric fluid intake, such as water, is permitted. This is a major discrepancy between religious and non-religious fasting and consequently considerably decreases the risk of dehydration and hypotension in non-religious fasting. ${ }^{7}$ In Ramadan, which is the ninth month of the Islamic calendar, Muslims religiously fast and abstain from eating or drinking anything from dawn to dusk. Muslim women have their point of view regarding OCP as some of them tend to use a short course of OCP to postpone their period during the holy month of Ramadan, or during the Hajj ceremony to devote themselves to worship since they are not obligated to worship during their menstruation. ${ }^{6,8,9}$ Therefore, this study aim to identify the prevalence, clinical characteristics, risk factors and management of CVT among fasting women using OCPs during the holy month of Ramadan. From

Disclosure. Authors have no conflict of interests, and the work was not supported or funded by any drug company. these preliminary data, we aim to enhance the standard of care to improve women's health.

Methods. This retrospective study was carried out using the database of acute stroke units as well as the patient medical records in the thrombosis clinic at King Fahad Medical City, Riyadh, Saudi Arabia. Data was collected from June 2016 to June 2017. We also communicated with each patient that fit the inclusion criteria to complete any missing data in the patient's medical record. This study was approved by King Fahad Medical City (KFMC) Institutional Review Board.

All patients diagnosed with CVT confirmed by signs and symptoms, CT, or magnetic resonance imaging were included in this study. While patients not using OCP, male patients, pregnant women, and patients diagnosed with cancer were excluded from this study.

The study participants were categorized into 2 groups: i) the fasting group during the Holy month of Ramadan, and ii) the non-fasting group. The collected data included demographic characteristics (age at diagnosis, body mass index [BMI], and marital status), generations and duration of used OCP based on the estradiol component, affected sites of cerebral venous sinuses and veins (radiological findings), signs and symptoms of CVT (headache, seizure, vomiting, blurred vision, impaired consciousness, weakness, numbness, ache, confusion, double vision, abdominal pain, neck stiffness, neurological deficit, photophobia, phonophobia, back pain, fever with rigors, dizziness, vertigo, fever without rigors, hearing loss), risk factors of CVT (prothrombin gene mutation, protein $S$ deficiency, protein C deficiency, antiphospholipid workup, dehydration, family history of CVT, history of surgery, systemic lupus erythematosus, and management (initiation and maintenance anticoagulation therapy, duration of anticoagulation).

Statistical analysis. Literature review was performed using major databases such as PubMed, Web of Science, and Google Scholar. Descriptive statistics were used to describe the outcome variables (patients' demographics, clinical presentation, prevalence, and risk factors). Statistical Package for Social Sciences, version 23 (IBMCorp, Armonk, NY, USA) was used to enter and analyze all data. An independent t-test was used to compare continuous variables, and a Chi-square test was used to compare categorical variables, and $p$-value of $<0.05$ was considered statistically significant.

Results. Out of 108 female patients with CVT, 39 (36.1\%) were secondary to OCP, of whom 16 (41\%) participants were fasting. No statistically significant 
difference found in the demographic characteristics between the non-fasting and fasting groups (Table 1).

The majority of both non-fasting ( $n=14: 60.9 \%)$ and fasting groups $(\mathrm{n}=8: 50 \%)$ used the third generation of OCP. No statistically significant difference found in the generations and the duration of using OCP between the non-fasting and fasting groups $(p=0.32)(p=0.073)$, respectively (Table 2).

The most affected sites in the non-fasting group were transverse sinus, sigmoid sinus, and superior sagittal sinus. Similarly, the topmost affected sites in the fasting group were transverse sinus $(80 \%)$, sigmoid sinus $(60.0 \%)$, and superior sagittal sinus $(60 \%)$ (Table 3).

The most prevalent symptom in the non-fasting group was headache $(100 \%)$, followed by seizure (56.5\%), vomiting (43.5\%), blurred vision (30.4\%), impaired consciousness (26.1\%) and weakness $(26.1 \%)$. Whereas, in the fasting group, the most prevalent symptoms were headache $(93.8 \%)$, vomiting $10(62.5 \%)$, seizure (50\%), and neurological deficit (40\%) (Table 4). Holocephalic headache was more common amongst fasting group $(68.8 \%)$ compared to non- fasting group $(30.4 \%)$. A statistically significant difference was only found in the prevalence of holocephalic headache between the 2 groups $(p=0.025)$.

The most common risk factor among the non-fasting group was protein S deficiency (13\%). Whereas dehydration was the most common risk factor among the fasting group (60\%). Protein S deficiency and dehydration risk factors were more common amongst fasting groups $(p=0.027)$ compared to the non-fasting group ( $p=0.003)$. (Table 5).

Unfractionated heparin was the most common anticoagulant therapies used during the initiation phase

Table 1 - Demographic characteristics of the study participants $(\mathrm{N}=39)$.

\begin{tabular}{lcccc}
\hline Variable & $\begin{array}{c}\text { Total number } \\
\text { of participants }\end{array}$ & $\begin{array}{c}\text { Non-fasting } \\
(\mathbf{n}=23)\end{array}$ & $\begin{array}{c}\text { Fasting } \\
(\mathbf{n}=16)\end{array}$ & $P$-value \\
\hline Age at diagnosis (years) & & & \\
$<30$ & $13(33.3)$ & $10(43.5)$ & $3(18.8)$ & \\
$30-40$ & $13(33.3)$ & $8(34.8)$ & $5(31.3)$ & 0.133 \\
$40-50$ & $13(33.3)$ & $5(21.7)$ & $8(50.0)$ & \\
Marital status & $36(92.3)$ & $21(91.3)$ & $15(93.8)$ & 0.823 \\
Yes & $3(7.7)$ & $2(8.7)$ & $1(6.3)$ \\
No & $31.9 \pm 5.8$ & $32.0 \pm 5.9$ & $31.8 \pm 5.9$ & 0.917 \\
BMI $\left(\mathrm{kg} / \mathrm{m}^{2}\right)$ & \multicolumn{5}{c}{ BMI: body mass index } \\
\multicolumn{5}{c}{ Data are presented either as numbers and percentages (\%). } \\
\hline \multicolumn{5}{c}{}
\end{tabular}

Table 2 - Generations and the duration of using oral contraceptive pills by the study participants.

\begin{tabular}{lcccc}
\hline $\begin{array}{l}\text { Generations \& } \\
\text { duration }\end{array}$ & $\begin{array}{c}\text { Total number } \\
\text { of participants } \\
(\mathrm{N}=39)\end{array}$ & $\begin{array}{c}\text { Non-fasting } \\
(\mathbf{n}=23)\end{array}$ & $\begin{array}{c}\text { Fasting } \\
(\mathbf{n}=16)\end{array}$ & $P$-value \\
\hline $\begin{array}{l}\text { Generations of OCP } \\
\text { First generation }\end{array}$ & $1(2.6)$ & 0 & $1(6.3)$ & \\
Second generation & $2(5.1)$ & 0 & $2(12.5)$ & \\
Third generation & $22(56.4)$ & $14(60.9)$ & $8(50.0)$ & 0.32 \\
Fourth generation & $8(20.5)$ & $5(21.7)$ & $3(18.8)$ & \\
Unknown & $6(15.4)$ & $4(17.4)$ & $2(12.5)$ & \\
Duration of OCP use & & & & \\
$<1$ month & $3(7.7)$ & 0 & $3(18.7)$ & \\
1-3 months & $10(25.6)$ & $7(30.4)$ & $3(18.7)$ & \\
3-6 months & $8(20.5)$ & $3(13.0)$ & $5(31.3)$ & 0.073 \\
6-12 months & $4(10.3)$ & $3(13.0)$ & $1 \quad(6.3)$ & \\
$>12$ months & $13(33.3)$ & $10(43.5)$ & $3(18.7)$ & \\
Unknown & $1(2.6)$ & 0 & $1 \quad(6.3)$ & \\
\hline
\end{tabular}

Data are presented as numbers and percentages (\%). OCP: oral contraceptive pill

Table 3 - Affected sites of cerebral venous sinuses and veins.

\begin{tabular}{lccc}
\hline Sites & $\begin{array}{c}\text { Total } \\
\text { number of } \\
\text { participants } \\
(\mathbf{N}=39)\end{array}$ & $\begin{array}{c}\text { Non-fasting } \\
(\mathbf{n}=23)\end{array}$ & $\begin{array}{c}\text { Fasting } \\
(\mathbf{n}=16)\end{array}$ \\
\hline Transverse sinus & $28(77.8)$ & $16(76.2)$ & $12(80.0)$ \\
Sigmoid sinus & $24(66.7)$ & $15(71.4)$ & $9(60.0)$ \\
Superior sagittal sinus & $19(52.8)$ & $10(47.6)$ & $9(60.0)$ \\
Internal jugular vein & $17(47.2)$ & $9(42.9)$ & $8(53.3)$ \\
Cortical vein & $3(8.3)$ & $3(14.3)$ & 0 \\
Cavernous sinus & $3(8.3)$ & 0 & $3(20.0)$ \\
Straight sinus & $2(5.6)$ & $2(9.5)$ & 0 \\
Internal cerebral vein & $2(5.6)$ & $1(4.8)$ & $1 \quad(6.7)$ \\
Vein of galen & $1(2.8)$ & $1(4.8)$ & 0 \\
Deep vein thrombosis & $4(10.5)$ & $3(13.0)$ & $1 \quad(6.7)$ \\
Pulmonary embolism & $3(7.9)$ & $1(4.3)$ & $2(13.3)$ \\
\hline
\end{tabular}

Data are presented as numbers and percentages. (\%)

for non-fasting (36.4\%) and fasting groups (50\%). During the maintenance phase, Warfarin (59.1\%) and Rivaroxaban $(31.8 \%)$ were the most commonly used treatment for the non-fasting group. In comparison, in the fasting group, Rivaroxaban (50\%) was more commonly used than Warfarin (43.8\%) (Table 6). 
Table 4 - Signs and symptoms of cerebral venous thrombosis among the study participants.

\begin{tabular}{|c|c|c|c|c|}
\hline $\begin{array}{l}\text { Signs and } \\
\text { symptoms }\end{array}$ & $\begin{array}{c}\text { Total number } \\
\text { of participants } \\
(\mathrm{N}=39)\end{array}$ & $\begin{array}{c}\text { Non-fasting } \\
(\mathrm{n}=23)\end{array}$ & $\begin{array}{l}\text { Fasting } \\
(\mathrm{n}=16)\end{array}$ & $P$-value \\
\hline Headache & $38(97.4)$ & $23(100)$ & $15(93.8)$ & 0.421 \\
\hline \multicolumn{5}{|l|}{ Site of headache } \\
\hline Left & $14(35.9)$ & $7(30.4)$ & $7(43.8)$ & 0.503 \\
\hline Right & $12(30.8)$ & $7(30.4)$ & $5(31.3)$ & 1.000 \\
\hline Frontal & 7 (17.9) & $4(17.4)$ & $3(18.8)$ & 1.000 \\
\hline Parietal & $1 \quad(2.6)$ & $0 \quad(0.0)$ & $1 \quad(6.3)$ & 0.410 \\
\hline Temporal & $3(7.7)$ & $1 \quad(4.3)$ & $2(12.5)$ & 0.557 \\
\hline Occipital & $10(25.6)$ & $4(17.4)$ & $6(37.5)$ & 0.264 \\
\hline Holocephalic & $18(46.2)$ & $7(30.4)$ & $11(68.8)$ & 0.025 \\
\hline Hemicrania & $6(15.4)$ & $3(13.0)$ & $3(18.8)$ & 0.674 \\
\hline \multicolumn{5}{|l|}{ Type of headache } \\
\hline Constant dull & $5(12.8)$ & $2(8.7)$ & $3(18.8)$ & 0.631 \\
\hline Piercing & $2(5.1)$ & $1 \quad(4.3)$ & $1 \quad(6.3)$ & 1.000 \\
\hline Throbbing & $5(12.8)$ & $3(13.0)$ & $2(12.5)$ & 1.000 \\
\hline Thunderclap & $2(5.1)$ & $\begin{array}{ll}0 & (0.0)\end{array}$ & $2(12.5)$ & 0.162 \\
\hline Seizures & $21(53.8)$ & $13(56.5)$ & $8(50.0)$ & 0.688 \\
\hline Vomiting & $20(51.3)$ & $10(43.5)$ & $10(62.5)$ & 0.242 \\
\hline Blurred vision & $13(33.3)$ & $7(30.4)$ & $6(37.5)$ & 0.645 \\
\hline $\begin{array}{l}\text { Impaired } \\
\text { consciousness }\end{array}$ & $8(20.5)$ & $6(26.1)$ & $2(12.5)$ & 0.432 \\
\hline Weakness & $11(28.9)$ & $6(26.1)$ & $5(33.3)$ & 0.734 \\
\hline Numbness & $6(15.8)$ & $5(21.7)$ & $1(6.7)$ & 0.370 \\
\hline Ache & $8(20.5)$ & $4(17.4)$ & $4(25.0)$ & 0.694 \\
\hline Confusion & $6(15.4)$ & $4(17.4)$ & $2(12.5)$ & 1.000 \\
\hline Double vision & $5(12.8)$ & $4(17.4)$ & $1 \quad(6.3)$ & 0.631 \\
\hline Abdominal pain & $6(15.8)$ & $4(17.4)$ & $2(13.3)$ & 1.000 \\
\hline Neck stiffness & $4(10.5)$ & $4(17.4)$ & $0(0.0)$ & 0.130 \\
\hline $\begin{array}{l}\text { Neurological } \\
\text { deficit }\end{array}$ & $10(26.3)$ & $4(17.4)$ & $6(40.0)$ & 0.264 \\
\hline Photophobia & $5(12.8)$ & $3(13.0)$ & $2(12.5)$ & 1.000 \\
\hline Phonophobia & $4(10.5)$ & $2(8.7)$ & $2(13.3)$ & 1.000 \\
\hline Back pain & $3(7.9)$ & $2(8.7)$ & $1 \quad(6.7)$ & 1.000 \\
\hline Fever with rigors & 1 & $1 \quad(4.3)$ & $\begin{array}{ll}0 & (0.0)\end{array}$ & 1.000 \\
\hline Dizziness & $2(5.3)$ & $1 \quad(4.3)$ & $1 \quad(6.7)$ & 1.000 \\
\hline Vertigo & $5(13.2)$ & $1 \quad(4.3)$ & $4(26.7)$ & 0.139 \\
\hline $\begin{array}{l}\text { Fever without } \\
\text { rigors }\end{array}$ & $2(5.1)$ & $\begin{array}{ll}0 & (0.0)\end{array}$ & $2(12.5)$ & 0.162 \\
\hline Hearing loss & $1 \quad(2.6)$ & $0 \quad(0.0)$ & $1 \quad(6.3)$ & 0.410 \\
\hline
\end{tabular}

Significant variable are in bold. Data are presented as numbers and percentages (\%).

Discussion. In general, although most studies have been observational, intermittent fasting has shown to potentially support improvement of the lipid profile of patients, reducing their total cholesterol, low density lipoprotein triglycerides, and helping increase high-density lipoprotein levels and decrease blood pressure, and improve markers of cardiovascular risk. ${ }^{10}$ However, the literature also shows that it could be counterproductive to have shown that an excessive energy deficit could be counterproductive for improving when attempting to improve the lipid profile. ${ }^{11}$ Fasting
Table 5 - Risk factors of cerebral venous thrombosis among the study participants.

\begin{tabular}{|c|c|c|c|c|}
\hline Risk Factor* & $\begin{array}{c}\text { Total number } \\
\text { of participants } \\
(\mathrm{N}=39)\end{array}$ & $\begin{array}{c}\text { Non-fasting } \\
\quad(\mathbf{n}=23)\end{array}$ & $\begin{array}{l}\text { Fasting } \\
(\mathrm{n}=16)\end{array}$ & $P$-value \\
\hline $\begin{array}{l}\text { Protein S } \\
\text { deficiency }\end{array}$ & $12(30.8)$ & $3(13.0)$ & $8(50.0)$ & 0.027 \\
\hline $\begin{array}{l}\text { Protein C } \\
\text { deficiency }\end{array}$ & $5(12.8)$ & $1(4.3)$ & $4(25.0)$ & 0.139 \\
\hline $\begin{array}{l}\text { Prothrombin gene } \\
\text { mutation }\end{array}$ & $1 \quad(2.6)$ & $0(0.0)$ & $1 \quad(6.3)$ & 0.410 \\
\hline Antiphospholipid & $2(5.3)$ & $1(4.5)$ & $1 \quad(6.3)$ & 1.000 \\
\hline Dehydration & $11(29.7)$ & $2(8.7)$ & $9(60.0)$ & 0.003 \\
\hline $\begin{array}{l}\text { Family history of } \\
\text { CVT }\end{array}$ & $5(12.8)$ & $2(8.7)$ & $3(18.8)$ & 0.631 \\
\hline History of surgery & $1 \quad(2.6)$ & $1(4.5)$ & 0 & 1.000 \\
\hline SLE & $1 \quad(2.7)$ & $1(4.5)$ & 0 & 1.000 \\
\hline
\end{tabular}

and dehydration appear to worsen the contraceptive side effects on circulation, which is concentrated in the blood because of low water intake and triggers thrombotic events associated with it. The results of this study indicated that $41 \%$ of our patients were diagnosed with CVT had used a brief course of OCP during Ramadan, which was in agreement with previous studies conducted in Iran by Khomand et al, ${ }^{6}$ stated that the CVT rate is significantly high in consumers of OCPs in Ramadan. A cohort study conducted during 4 consecutive Ramadans (2006-2009) in Iran found a 5 -fold increase in the incidence of CVT in the month of Ramadan. ${ }^{12}$ Approximately, $79 \%$ of female CVT cases in the months of Ramadan had a short-term history of consuming OCPs. Distinctively, the consumption of OCPs was found in $34.3 \%$ of female CVT cases diagnosed in non-Ramadan months. ${ }^{12}$ Another recent study carried out in Hamadan, Iran demonstrated fasting patients using OCPs caused CVT with more severe both focal neurological deficit (64.5\%) and hemorrhage (66.7\%). ${ }^{13}$ Finally, another case-control study carried out in Shiraz, Iran showed that compared to the rest of the year, 38 CVT patients demonstrated a significant rise in Ramadan and they were 1.4 times more likely to develop CVT during Ramadan. ${ }^{14} \mathrm{~A}$ previous study by Zuurbier et $\mathrm{al},{ }^{15}$ indicated that obesity (BMI $\geq 30$ ) is associated with an increased risk of CVT for those using OCPs (odd ratio: $2.63 ; 95 \% \mathrm{CI}$, 1.53-4.54). However, our results showed that there is no statistically significant difference in the demographic characteristics (age at diagnosis of CVT, marital status, and $\mathrm{BMI}$ ) between the non- fasting and fasting groups using the OCPs. 
Table 6 - Management of cerebral venous thrombosis.

\begin{tabular}{lcccc}
\hline Management type & $\begin{array}{c}\text { Total number } \\
\text { of participants } \\
(\mathrm{N}=39)\end{array}$ & $\begin{array}{c}\text { Non-fasting } \\
(\mathrm{n}=23)\end{array}$ & $\begin{array}{c}\text { Fasting } \\
(\mathrm{n}=16)\end{array}$ & P-value \\
\hline $\begin{array}{l}\text { Catheter-directed intracerebral thrombolysis } \\
\text { Initiation anticoagulation }\end{array}$ & $1(2.6)$ & $0(0.0)$ & $1(6.7)$ & 0.410 \\
$\quad$ Unfractionated heparin & $16(42.1)$ & $8(36.4)$ & $8(50.0)$ & \\
LMWH (Enoxaparin) & $12(31.6)$ & $7(31.8)$ & $5(31.3)$ & 0.355 \\
Vitamin K antagonist (Warfarin) & $9(23.7)$ & $7(31.8)$ & $2(12.5)$ & \\
Factor Xa inhibitors (Rivaroxaban) & $1(2.6)$ & $0(0.0)$ & $1(6.3)$ & \\
Maintenance anticoagulation & & & & \\
Vitamin K antagonist (Warfarin) & $20(52.6)$ & $13(59.1)$ & $7(43.8)$ & \\
Factor Xa inhibitors (Rivaroxaban) & $15(39.5)$ & $7(31.8)$ & $8(50.0$ & 0.579 \\
LMWH (Enoxaparin) & $2(5.3)$ & $1(4.5)$ & $1(6.3)$ & \\
Direct thrombin inhibitors (Dabigatran) & $1(2.6)$ & $1(4.5)$ & $0(0.0)$ & \\
Duration of anticoagulation & & & & \\
$<6$ months & $9(23.7)$ & $4(18.2)$ & $5(31.3)$ & 0.591 \\
6-12 months & $12(31.6)$ & $8(36.4)$ & $4(25)$ & \\
$>12$ months & $17(44.7)$ & $10(45.5)$ & $7(43.8)$ & \\
\hline
\end{tabular}

Data presented as numbers and percentages (\%). LMWH: low-molecular-weight heparin

Our results indicated that a vast majority of our patients used third-generation contraceptives that contain(Ethinylestradiol/Desogestrelorethinylestradiol/ gestodene). A case-control study showed that women who use combined oral contraceptives (COCs) have a heightened risk of CVT. ${ }^{8}$

In our study, the most affected site of CVT amongst the 2 groups was transverse sinus, followed by sigmoid sinus, superior sagittal sinus, and internal jugular vein. While a study carried out in China showed that most lesions affected were superior sagittal, transverse, and sigmoid sinuses. ${ }^{16}$

Our results were in agreement with a previous study, which was a retrospective case series conducted in Iran from 2014-2015, where 9 females were treated with OCPs for more than a month to be able to fast during Ramadan. This study correlates with our findings of headaches, seizures, and vomiting being the most common symptoms. The case series reported the most frequent symptoms to be a headache (100\%), followed by vomiting (55.5\%) and vertigo (44.4\%). ${ }^{5}$ Another retrospective study conducted by Kajtani et al, ${ }^{17}$ revealed that headaches $(77.3 \%)$, seizures $(54.5 \%)$, focal neurological signs (54.5\%), and decreased levels of consciousness $(50 \%)$ were the most prevalent symptoms of CVT. In addition, our results showed that holocephalic headache was more common amongst the fasting group compared to the non-fasting group $(p=0.025)$.

Dehydration was the most common risk factor among the fasting group in our study. Inconsistent with a previous study, ${ }^{6}$ our results showed that dehydration is a significant predisposing risk factor for CVT for women using OCP during Ramadan, particularly when this month comes during the summer (with avoidance of drinking water/fluids for up to 16 hours). The month of Ramadan varies because the Islamic calendar is a lunar calendar (a calendar based on the monthly cycles of the moon's phases) consisting of 12 lunar months in a year of 354 or 355 days. ${ }^{9}$ Muslim women have a different use of OCPs, during Ramadan. Since they are not obligated to worship during their menstruation, they tend to use a short course of OCP to postpone their period during the holy month of Ramadan and during the Hajj ceremony to devote themselves to worship. ${ }^{6,12}$ There also have been studies that suggested that dehydration has a pathophysiological link to the development of thrombosis after long-haul flights. ${ }^{18}$

Thrombophilia protein $S$ deficiency was found to be the most frequent risk factor in the non-fasting group. Venous thrombosis risk is increased with blood clotting disorders (hypercoagulable states), for example the G1691A mutation of the factor $V$ gene which promotes resistance to activated protein $\mathrm{C}$, and antithrombin III, protein $\mathrm{C}$, or protein $\mathrm{S}$ deficiencies. ${ }^{19}$ It has been shown previously that CVT is linked with factor V mutation and happens more frequently in younger women who are either receiving OCP, who are pregnant, or who are postpartum. An association was shown between OCP use and CVT in a study by Martinelli et $a l,{ }^{20}$ with a substantial risk increase when OCP is taken and the prothrombin-gene mutation is also present. In our 
study, 12 (30.8\%), a statistically significant number of participants were found to have thrombophilia protein $S$ deficiency ( $p=0.027$ ).

Regarding management, in our study, unfractionated heparin was the most common anticoagulant therapy used during the initiation phase for non-fasting and fasting groups. This is in line with the 2014 American Heart Association/American Stroke Association (AHA/ ASA) guidelines for the prevention of stroke and the 2017 European Stroke Organization guidelines for the diagnosis and treatment of CVT, which recommend adjusted-dose UFH or weight-based LMWH at a therapeutic dose to treat adult patients with acute CVT, including those with an intracerebral hemorrhage at baseline. $^{21,22}$

In our study, during the maintenance phase, Warfarin and Rivaroxaban were the most commonly used treatment for the non-fasting group, while in the fasting group Rivaroxaban was more frequently used than Warfarin. This is in accordance with the 2011 AHA/ ASA guidelines that suggest using vitamin $\mathrm{K}$ antagonists after initiation therapy with heparin, regardless of the presence of intracerebral hemorrhage. ${ }^{23}$ Guidelines from the American College of Chest Physicians issued in 2012 suggest that patients can be switched to oral anticoagulation, which is generally continued for a period of 3 to 6 months. ${ }^{24}$ However, small studies showed that direct oral anticoagulants have a similar clinical benefit as vitamin $\mathrm{K}$ antagonists (VKAs) in the treatment of CVT. Direct oral anticoagulants offer several advantages over VKAs, such as predictable dose-response, fewer drug and food interactions, and no need for laboratory monitoring of the International Normalized Ratio. ${ }^{25,26}$

Those women who have known thrombogenic mutations should use progestogen-only contraceptives, including levonorgestrel-releasing intrauterine devices rather than combined hormonal contraceptives. Due to the low incidence of the condition and high costs associated with screening, routine screening is not recommended. The preferred and most cost-effective thrombophilia screening method for women who are planning to conceive is to selectively recommend screening based on their previous personal or family history of previous extra-cerebral or cerebral venous thromboembolism events. Women with a family history of thromboembolism should be advised against taking combined oral contraceptives. Furthermore, the accessibility of OCP as an over-the-counter medication results in increased self-treatment with OCP that can exacerbate the problem in the Kingdom of Saudi Arabia. These are growing health problems that originate from cultural beliefs and should alarm the health services to solve this cultural problem and control the prescription of OCPs. We also specifically recommend the control of over-the-counter pills. We should provide information and warnings to all women who are taking OCP, particularly during fasting months in the summer season, as the incidence of CVT is higher. Patients should be advised to have adequate hydration and lifestyle modification through educational campaigns on the vascular risks of OCP use during Ramadan. A multi-center prospective cohort study is recommended to assess the impact of women exposed to OCPs during this time.

The assessment of dehydration was based on subjective methods such as fluid intake during the evening hours and urine color. However, the ideal objective method of assessing hydration is physical signs such as a furrowed tongue, dry mucous membranes, and lack of skin turgor, in addition to laboratory tests of urine specific gravity, urine osmolality, serum osmolality, serum sodium, and BUN-creatinine ratio. ${ }^{27,28}$ Urine analysis appeared to be the single most useful tool for assessing hydration. Armstrong color chart for monitoring hydration found a moderate positive correlation between urine color and both specific gravity and osmolality and also between osmolality and serum sodium and the BUN-creatinine ratio. $^{29}$

Study limitations. The retrospective design poses as the main limitation of this study, where potential confounding of other unmeasured factors could affect the results in addition to some missing data from the patients' chart. Secondly, data were collected from a single-center which limited the sample size. In addition, we could not collect systematic data regarding the quantity of fluids taken during the permissible non-fasting night hours. Lastly, there was no control group to compare outcomes and assess risk. Hence, a multi-center case-control study is needed.

In conclusion, the findings of this study showed OCP use is a significant risk factor for CVT. Women exposed to OCPs during Ramadan are at a higher risk of developing CVT. Dehydration and protein S deficiency were identified as 2 prominent risk factors amongst the fasting group and the non-fasting group respectively. Therefore, all women who are using OCP (whether prescribed or over-the-counter) should undergo formal, written risk assessments for factors of CVT, either by the physician who prescribed the medication or the pharmacist who dispensed it in the community's pharmacy.

Our study suggests that the side effects of OCPs use might outweigh its benefits, specifically in the fasting 
population; thus, it should be prescribed with caution. Another implication on patient education for the fasting patients is to advise them to stay hydrated by drinking fluids during all the permissible night hours.

Acknowledgment. The authors gratefully acknowledge King Fahad Medical City (KFMC), Riyadh, Saudi Arabia and its Research Center for their tremendous support and the Institutional Review Board of KFMC for the ethical approval of this study. The authors would also like to thank Enago (www.enago.com) for English language editing.

\section{References}

1. Tadi P, Behgam B, Baruffi S. Cerebral Venous Thrombosis. StatPearls. Treasure Island (FL): StatPearls Publishing LLC; 2020.

2. Algahtani HA, Abdu AP, Shami AM, Hassan AE, Madkour MA, Al-Ghamdi SM, et al. Cerebral venous sinus thrombosis in Saudi Arabia. Neurosciences (Riyadh) 2011; 16:329-334.

3. Bousser MG, Ferro JM. Cerebral venous thrombosis: an update. Lancet Neurol 2007; 6: 162-170.

4. dos Santos VM, Andrade LM, Leal CT, de Souza LA, Lima RLM, Nogueira AL. Two women with cerebral venous thrombosis: oral contraceptives? West Indian Med J 2013; 62: 260-263.

5. Amoozegar F, Ronksley PE, Sauve R, Menon BK. Hormonal contraceptives and cerebral venous thrombosis risk: a systematic review and meta-analysis. Front Neurol 2015; 6: 7.

6. Khomand P, Hassanzadeh K. A case-series study of cerebral venous thrombosis in women using short course oral contraceptive. Iran J Neurol 2016; 15: 92-95.

7. Grajower MM, Horne BD. Clinical management of intermittent fasting in patients with diabetes mellitus. Nutrients 2019; 11: 873.

8. Saadatnia M, Tajmirriahi M. Hormonal contraceptives as a risk factor for cerebral venous and sinus thrombosis. Acta Neurol Scand 2007; 115: 295-300.

9. Bearman P, Bianquis Th, Bosworth CE, van Donzel E, Heinrichs WP. Encyclopaedia of Islam 2nd ed. Leiden (NL): Brill Academic Publishers; 2006.

10. Santos HO, Macedo RCO. Impact of intermittent fasting on the lipid profile: Assessment associated with diet and weight loss. Clinical Nutrition ESPEN 2018; 24: 14-21.

11. Meng H, Zhu L, Kord-Varkaneh H, Santos HO, Tinsley GM, Fu P. Effects of intermittent fasting and energy-restricted diets on lipid profile: A systematic review and meta-analysis. Nutrition 2020; 77: 110801.

12. Sasannejad P, Mellat Ardekani A, Velayati A, Shoeibi A, Saeidi $\mathrm{M}$, Foroughipour $\mathrm{M}$, et al. Cerebral vein thrombosis in women using short course oral contraceptive consumption. Iran J Reprod Med 2012; 10: 537-542.

13. Ghiasian M, Mansour M, Moradian N. Prognosis of fasting in patients with cerebral venous thrombosis using oral contraceptives. Iran J Neurol 2019; 18: 82-84.

14. Javanmardi H, Safari A, Borhani-Haghighi A. Effect of Ramadan fasting in incidence of cerebral venous sinus thrombosis. Int J Stroke 2017; 13: NP2.

15. Zuurbier SM, Arnold M, Middeldorp S, et al. Risk of cerebral venous thrombosis in obese women. JAMA Neurol 2016; 73: 579.
16. Wang X, Sun X, Liu H. Clinical analysis and misdiagnosis of cerebral venous thrombosis. Exp Ther Med 2012; 4: 923-927.

17. Kajtazi NI, Zimmerman VA, Arulneyam JC, Al-Shami SY, Al-Senani FM. Cerebral venous thrombosis in Saudi Arabia. Clinical variables, response to treatment, and outcome. Neurosciences (Riyadh) 2009; 14: 349-354.

18. Linked In. Sylvia Haas's Antithrombotics Weekly - Week 21 Thrombosis Management Barcelona. [Updated 2016 August 22. Accessed 2018 June 12]. Available from URL: https://www. linkedin.com/pulse/sylvia-haass-antithrombotics-weekly-week21-thrombosis-sylvia-haas/

19. De Stefano V, Finazzi G, Mannucci PM. Inherited thrombophilia: pathogenesis, clinical syndromes, and management. Blood 1996; 87: 3531-3544.

20. Martinelli I, Sacchi E, Landi G, Taioli E, Duca F, Mannucci PM. High risk of cerebral-vein thrombosis in carriers of a prothrombin-gene mutation and in users of oral contraceptives. N Engl J Med 1998; 338: 1793-1797.

21. Ferro JM, Bousser MG, Canhão P, Coutinho JM, Crassard I, Dentali F, et al. European Stroke Organization guideline for the diagnosis and treatment of cerebral venous thrombosis endorsed by the European Academy of Neurology. Eur J Neurol 2017; 24: 1203-1213.

22. Kernan WN, Ovbiagele B, Black HR, Bravata DM, Chimowitz Marc I, Ezekowitz Michael D, et al. Guidelines for the prevention of stroke in patients with stroke and transient ischemic attack. Stroke 2014; 45: 2160-2236.

23. Saposnik G, Barinagarrementeria F, Brown RD, Bushnell CD, Cucchiara B, Cushman M, et al. Diagnosis and management of cerebral venous thrombosis. Stroke 2011; 42: 1158-1192.

24. Lansberg MG, O’Donnell MJ, Khatri P, Lang ES, NguyenHuynh MN, Schwartz NE, et al. Antithrombotic and thrombolytic therapy for ischemic stroke: Antithrombotic Therapy and Prevention of Thrombosis, 9th ed: American College of Chest Physicians Evidence-Based Clinical Practice Guidelines. Chest 2012; 141 (2 Suppl): e601S-e636S.

25. Geisbüsch C, Richter D, Herweh C, Ringleb Peter A, Nagel S. Novel factor xa inhibitor for the treatment of cerebral venous and sinus thrombosis: first experience in 7 patients. Stroke 2014; 45: 2469-2471.

26. Anticoli S, Gul R, Chong J, Tan C, Pozzessere C. Treatment of cerebral venous thrombosis with rivaroxaban. J Biomedical Sci 2016; 5: 3 .

27. Alam I, Gul R, Chong J, Tan CT, Chin HX, Wong G, et al. Recurrent circadian fasting (RCF) improves blood pressure, biomarkers of cardiometabolic risk and regulates inflammation in men. J Transl Med 2019; 17: 272

28. Begum NB, Johnson SC. A review of the literature on dehydration in the institutionalized elderly. Clin Nutr 2010: e47-e53.

29. Wakefield B, Mentes J, Diggelmann D, Culp K. Monitoring hydration status in elderly veterans. West J Nurs Res 2002; 24 : 132-142. 